\title{
Statement of the Public Affairs Committee of the Teratology Society on the Importance of Smoking Cessation During Pregnancy
}

\author{
Jane Adams, Ph.D. ${ }^{1}$
}

${ }^{1}$ Department of Psychology, University of Massachusetts Boston

Corresponding author: Jane Adams, Ph.D.

Department of Psychology

University of Massachusetts Boston

100 Morrissey Blvd

Boston, MA 02125

Voice 617-287-6346

Email: jane.adams@umb.edu

Acknowledgements: The Committee and author of this statement wish to thank Patricia Janulewicz for supportive "reference-mining" activities. 
Reports on the harmful effects of smoking during pregnancy began to proliferate during the 1980s. Since that time, numerous studies have firmly established the risks to the fetus that are associated with exposure. In 2001, the Surgeon General Report argued that the established adverse health consequences of smoking on women's health "compel(s) the Nation to make reducing and preventing smoking one of the highest contemporary priorities for women's health" (USDHHS, 2001). Herein, the Public Affairs Committee of the Teratology Society argues that the nation must make the reduction of women's smoking during pregnancy one of the highest priorities for fetal and child health. In the U.S., cigarette smoking is the single largest preventable risk factor for pregnancy-related morbidity and mortality (Dempsey and Benowitz, 2001). In this report, we first examine the current prevalence of smoking during pregnancy and its negative effects on the fetus and child. We then examine the benefits of smoking cessation during pregnancy and the success rates and characteristics of women who are able to quit smoking during pregnancy. We then address the causes of the adverse outcomes of pregnancy and examine whether complete smoking cessation or nicotine replacement therapy may be necessary to ameliorate the smoking-related effects on pregnancy outcome. Finally, we argue for the enactment of educational and treatment programs for smoking cessation that are targeted at the women at highest risks for smoking during pregnancy, and also argue for a clinical efficacy study that will examine the consequences of nicotine replacement therapy upon maternal and fetal health. 
Prevalence of Smoking Among Pregnant Women

National health statistics from 1998 indicated that $22 \%$ of all women 18 years and older smoke cigarettes (Surgeon General's Report, 2001). It is estimated that $12-24 \%$ of pregnant women smoke, with the lower figure coming from self-reported information and the higher figure from more direct surveys (in SGR, 2001). The National Center for Health Statistics compiled birth certificate data from 46 states recording between 1989 and 1998. These data showed a gradual decline in the self-reported prevalence of smoking during pregnancy from $19.5 \%$ in 1989 to $12.9 \%$ in 1998 . Analyses of these data suggested that the decline resulted from a decrease in smoking initiation among women as opposed to an increase in smoking cessation during pregnancy. This self-reported information derived from birth certificate data is likely to underestimate actual smoking consumption, but the data do allow reasonably accurate assessments of the influence of certain variables upon smoking prevalence. Most notable are the importance of age, race and educational level as determinants of a woman's likelihood of smoking. Prevalence is higher among 18-24 year old pregnant women than among younger or older mothers. American Indian or Alaskan Native women (20.2\%) and white women (16.2\%) are now most likely to smoke, while black women report intermediate levels $(9.6 \%)$, and lowest levels occur in Hispanic (4\%) and Asian or Pacific Islander women (3.1\%). Equally striking is the association between advanced education and reduced smoking prevalence during pregnancy $(\leq 8$ years $=11.7 \%, 9-11$ years $=25.5 \%, 12$ years $=16.8 \%, 13-15$ years $=9.6 \%$, and $\geq 16$ years $=2.2 \%$ ). Among women who reported smoking, $68.6 \%$ reported smoking less than 10 cigarettes/day, 27.6\% reported smoking 11-20 cigarettes/day and 
only $3.8 \%$ reported smoking more than 20 cigarettes/day. These levels of consumption are believed to underestimate actual smoking behavior because studies in which nicotine or its primary metabolite, cotinine, are measured directly in cord blood, maternal blood or urine samples consistently indicate intake levels higher than those recorded through selfreport (Ellard et al, 1996).

\section{Consequences of Smoking During Pregnancy}

Pregnancies among women who smoke are marked by increased risks for spontaneous abortion, perinatal placental abnormalities, birth complications, increased prematurity, low birth weight, sudden death, increased postnatal health problems in their infants, and possible neurobehavioral changes (Andres and Day, 2000; Castles, Adams, Melvin et al, 1999; Surgeon General Report, 1990; 2001; Levin and Slotkin, 1998). Smoking during pregnancy has not been associated with major malformations. Andres and Day (2000) summarized the literature on perinatal complications associated with smoking and indicated well-established associations between maternal smoking during pregnancy and increased risks for placenta previa, abruptio placentae, premature rupture of the membranes, prematurity, intrauterine growth retardation and sudden infant death syndrome. Indeed, it has been suggested that smoking accounts for $15 \%$ of premature births, 20-30\% of infants with low birthweight (Andres and Day, 2000), and approximately $24 \%$ of SIDs deaths (Pollack, 2001). Based on the meta-analysis of data from studies on pregnancy-related smoking risks, DiFranza and Lew (1995) suggested that smoking during pregnancy annually causes an estimated 19,000 to 141,000 tobaccoinduced miscarriages, 32,000 to 61,000 infants born with low birthweight, 14,000 to 
26,000 infant admissions to neonatal intensive care units, 1900 to 4800 infant deaths due to perinatal disorders, and 1200 to 2200 deaths from sudden infant death syndrome (SIDS). Taylor and Wadsworth (1987) reported that in a sample of over 12000 children born to women who smoked during pregnancy, maternal smoking significantly increased the incidence of bronchitis and of hospital admission for lower respiratory tract illness during the first 5 years of life. Prenatal and postnatal tobacco smoke exposure, which varies greatly across SES and racial/ethnic groups, also has been associated with increased childhood asthma (Olivetti, Kercsmar, and Redline, 1996; Weitzman, Gortmaker, and Walker, 1990; Klinnert et al, 2001). Further, a growing number of studies suggest that infants born to women who smoke during pregnancy may be at increased risk for childhood obesity (vonKries et al, 2002; review: Schwetz and Slikker, 2003). Exposure to secondhand tobacco smoke during pregnancy also increases the risks for having a low birth weight infant (Haddow et al, 1988; Martinez et al, 1994; Nafsted et al, 1998; Eskenazi, Prehn, and Christianson, 1995). There are also multiple reports associating smoking during pregnancy with compromised cognitive performance in the child (review by Levin and Slotkin, 1998; Streissguth, Martin, Barr, Sandman, Kirchner, and Darby, 1984; Kristjansson, Fried, and Watkinson, 1989). While the human situation presents many variables whose influences can be addressed only through statistical procedures, it is noteworthy that there are many studies in rodents attesting to neurobehavioral compromise and neurochemical alterations in offspring exposed to nicotine (review: Levin and Slotkin, 1998) or carbon monoxide (review: Tolcos, McGergor, Walker, Rees, 2000) during prenatal development. 
Benefits of Smoking Reduction and Cessation During Pregnancy

Fortunately, it has been shown that when a patient stops smoking in early pregnancy, infant birth rates increase in relation to the decrease in cotinine level ( $\mathrm{Li}$ et al, 1993). Women who quit smoking in the first 3-4 months of pregnancy are at no greater risks for having a low birth weight infant than are non-smoking women (USHHS, 1990) and smoking cessation also reduces the risks for having a premature infant (Lumley, Oliver, and Waters, 2000). Smoking cessation interventions for pregnant women result in fewer low-birth-weight newborns and perinatal deaths; fewer physical, cognitive, and behavioral problems during infancy and childhood; and important health benefits for the mother (Fiore et al, 2000). Thus, clear benefits to fetal and child health result when a woman stops smoking during pregnancy. The benefits of lesser smoking reduction or nicotine replacement therapy have not been empirically examined.

In recognition of some of the harmful effects of smoking during pregnancy and as a result of increased motivation, women are more likely to stop smoking during pregnancy than at other times (Report of the Surgeon General, 2001). Indeed, approximately $1 / 3$ of women stop smoking upon planning to become pregnant or learning that they are pregnant ( Walsh et al, 1997). Nevertheless, within 1 year after childbirth, the majority of mothers begin smoking again (Kahn et al, 2002), thus exposing their children to harmful effects of sidestream smoke. It is important to understand who is most likely to be a smoker during the child-bearing years and who is least likely to stop 
smoking during pregnancy so that treatment programs can be appropriately directed for highest benefit.

Research suggests that the women most likely to smoke are primarily 18-24 year old women with 9-11 years of education. Likewise, the women who are most likely to quit tend to represent groups who are least likely to smoke in the first place, such as older women and women with greater education (Kahn et al, 2002). This suggests that cessation programs must target groups of women who are more likely to smoke and less likely to quit. The women least likely to quit tend to be less educated women under the age of 25 who are also heavy smokers (Kahn et al, 2001). Smoking cessation programs designed and implemented on behalf of these women are essential.

\section{Nicotine versus Cigarette Smoke Constituents as Mediators of Risk}

The role played by different components of tobacco smoke in causing adverse effects on development is difficult to examine in human studies. Tobacco smoke contains more than 3000 chemicals (Hoffmann, Djordjevic, and Hoffmann, 1997). Within this plethora, nicotine and carbon monoxide have received the greatest attention in research studies, likely because nicotine is the primary psychoactive agent and the agent responsible for the addictive potency of cigarettes, and carbon monoxide is a major constituent of tobacco smoke with well-established effects on oxygen delivery. Human studies that have attempted to sort out the role of nicotine have shown dose-related effects between maternal levels of nicotine and a primary metabolite, cotinine, and risks for low birth weight. Low birth weight is the endpoint most often studied likely due to 
the ease and relative reliability of measurements as well as broad data availability in medical and birth certificate records. Nicotine readily crosses the placenta and cord serum samples show concentrations in the fetus that mirror or exceed maternal levels (Luck and Nau, 1984; Luck, Nau, Hansen, and Steldinger, 1985; Koren, 1995). Peacock et al (1991) compared birth weights in infants born to women who smoked low yield cigarettes (low nicotine and carbon monoxide) with that of higher content cigarettes and found a dose-related effect of nicotine and carbon monoxide on low birth weight. The authors argued that risks for reduced birthweight were primarily present among those who smoked the equivalent of 13 or more high yield cigarettes/day. Ellard et al (1996) examined the relationship between nicotine metabolite levels and birthweight deficits and found a dose-dependent relationship. They also reported that infants born to smokers had an average birthweight deficit of $226 \mathrm{~g}$. This is consistent with the Surgeon General Report of a deficit of approximately $200 \mathrm{~g}$ (SGR, 1990). The dose-response relationship suggests that perhaps babies exposed to secondhand smoke may also be at risk for reduced birthweight. Birthweight deficits among babies born to passive smokers have been estimated at approximately $100 \mathrm{~g}$ in work by Haddow et al (1998) and Martinez et al (1994). Krishna et al (1991) examined the effects of the use of smokeless tobacco during pregnancy, thereby removing tobacco smoke constituents as contributors to adverse outcome, and reported that the use of smokeless tobacco also reduces infant birthweight. The role of nicotine is also emphasized in numerous animal studies that control for other exposure variables (reviews by Levin and Slotkin, 1998; Lichtensteiger et al, 1988; Lambers and Clark, 1996). 
Research on the effects of exposure to the carbon monoxide in tobacco smoke have shown adverse effects upon placental and fetal physiology, fetal growth, brain development, neurochemistry and function (reviews: Dempsey and Benowitz, 2001; Levin and Slotkin, 1998; articles: Fechter and Annau, 1976, 1977, 1980; Mactutus and Fechter, 1984, 1985). Carbon monoxide binds to maternal and fetal hemoglobin sites with an affinity that is more than 200 times that of oxygen (Dempsey and Benowitz, 2001). In smokers, elevated carboxyhemoglobin levels interfere with normal placental function, maternal-fetal oxygen transport and fetal circulation. The fetal hypoxia that results has been argued to be a major cause of fetal growth retardation.

While progress has been made in understanding the contributions of nicotine and carbon monoxide to the adverse outcomes of pregnancy in women who smoke, it has also become clear that the responsible players are more likely a multitude of factors, such as altered metabolic, hormonal, neurochemical, enzymatic, immunologic, and other cellular morphological and physiological changes (Dempsey and Benowitz, 2001). As a result of contributions from multiple smoking constituents, smoking cessation during pregnancy is the optimal goal for the protection of maternal and fetal health. Nevertheless, given the potency of nicotine as an addictive drug, complete smoking cessation may not be a plausible goal for many pregnant women. Thus, it is critical that the benefits of nicotine replacement therapy as an aid to smoking cessation also be explored.

Recent research has indicated that vulnerability to the effects of smoking on infant birthweight may be associated with certain maternal metabolic genotypes. CYP1A1 and 
GSTT1 genotypes are particularly susceptible to reduced infant birthweight in response to maternal smoking (Wang et al, 2002). These genotypes fail to produce enzymes relevant to the conversion of toxic metabolites of cigarette smoke to less harmful compounds.

These data suggest that for women who smoke during pregnancy, smoking cessation is the optimal treatment to benefit fetal and child health. However, benefits may also result when nicotine levels are greatly reduced and other harmful constituents are removed through nicotine replacement therapy. In addition to targeting smoking cessation programs to women with the highest risk demographic features, it may also be helpful to identify women at increased risk due to the presence of these genetic polymorphisms.

\section{Characteristics of Effective Smoking Cessation Programs during Pregnancy}

Programs for reducing smoking during pregnancy include those designed for differing levels of targeted use with individual women, such as various forms of smoking cessation programs and nicotine replacement programs, and educational self-help programs designed with differing levels of specificity to the target populations. Increased cigarette prices have also been shown to be effective deterrents for many women. While $1 / 3$ of women elect to terminate smoking during pregnancy, the unsuccessful remainder benefit from intervention. High intensity, individualized interventions have been shown to increase quitting rates by about 8\% (Lumley, Oliver and Waters, 2000). In 1993, Walsh and Redman argued that cognitive behavioral counseling programs show the 
highest success rates. The two main factors associated with success appear to be involvement in an intense counseling program administered by medical, nursing, or other trained clinicians and exposure to self-help materials that are specific to the characteristics of the individual (Walsh et al, 2001). It is apparently ineffective to simply provide risk information to pregnant women, to enroll them in group behavior therapy programs, or to distribute self-help materials designed for a generic audience (Walsh et al, 2001). These findings are consistent with reports on the efficacy of different smoking cessation programs among the general population of smokers where a strong relationship has been shown between session length of person-to-person smoking cessation intervention programs and success in quitting (Fiore et al, 2000). As a result of these findings in studies of the general population of smokers, in 2000, the US Public Health Service published Clinical Practice Guidelines for Treating Tobacco Use and Dependence and recommended that high intensity interventions should be implemented with 4 or 5 counseling sessions conducted whenever feasible.

While intensive, individualized smoking cessation programs are most effective in achieving abstinence among smokers, other measures can be helpful in curtailing smoking or its initiation. Ringel and Evans (2001) investigated the effects of higher cigarette prices (due to excise tax increases) on consumption by pregnant women with particular attention to the effects on women at highest risks for adverse outcomes. Using natality data from 1989 (the first year smoking data were available) to 1995, they determined that for every $10 \%$ increase in price, smoking participation rates among pregnant women fall by $7 \%$. Further, pregnant women were found to be more responsive 
to tax increases in cigarette costs than is the general adult population. While most of the age, ethnic, and educational groups examined demonstrated responsiveness to the tax hikes, effects were most pronounced among women who have demographic characteristics associated with increased likelihood of quitting anyway during pregnancy: white women, older women, married women, and more educated women. Ringel and Evans (2001) did not find evidence to support that tax increases reduce the smoking consumption of women who continue to smoke during pregnancy. These data therefore support the concept that increases in excise taxes on cigarettes are effective adjunctive measures that assist in reducing smoking rates during pregnancy, and thereby are an aid to improving maternal and child health.

\section{Current Availability of Smoking Cessation Programs During Pregnancy}

A survey of HMO practices in the state of California during 1997 revealed that coverage of smoking cessation programs during pregnancy was limited (Pickett et al, 2001). The survey focused on coverage of individual, group, telephone counseling, and self-help kits and found that only $8 \%$ of HMOs provided all of these options, while $92 \%$ covered at least one treatment, and $8 \%$ provided no coverage for tobacco dependency treatment during pregnancy. In 2000, the Clinical Practice Guidelines for Treating Tobacco Use and Dependence (Fiore et al, 2000; US Public Health Service, 2000) which represent consensus by a consortium of 7 governmental and nonprofit organizations, argued that providing smoking cessation treatment options to all patients who smoke should become a standard practice of ethical medical care and that tobacco dependence treatments identified as effective should be a covered benefit of all insurance plans, both 
public and private (Fiore et al, 2000). To date, this is not yet mandatory and many women are denied coverage of smoking cessation programs during pregnancy.

\section{$\underline{\text { Necessary Actions }}$}

It is imperative that all health care practitioners, relevant governing bodies and public and private health care providers take further actions that will reduce smoking during pregnancy and thereby improve fetal outcome and child health. The Public Affairs Committee of the Teratology Society proposes that policies and actions must:

- Increase the availability of individualized, intensive counseling programs for smoking cessation to pregnant women

- Target increased availability to young women with less than a high school educational level who are heavy smokers

- Increase the smoking cessation program training of medical and other counseling professionals for service delivery to pregnant women

- Provide funding for the conduct of a large clinical trial study to determine the efficacy and risks associated with nicotine replacement therapy in women who are likely to be unsuccessful at quitting smoking during pregnancy

- Enact legislation calling for mandatory coverage of individualized smoking cessation programs during pregnancy by all private, state, and federal health insurance providers.

During the past several years, the World Health Organization has been working to gain consensus on a tobacco control treaty known as the Framework Convention on Tobacco Control. This treaty was passed on May 21, 2003 at the 56th World health 
Assembly. Treaty content obligates the countries that sign and ratify it to adopt bans on the advertising of tobacco products, to consider imposing higher taxes on tobacco, to require that all ingredients be listed on packaging, and to assign broader legal liability upon tobacco product manufacturers. As of June 20th, 2003, 40 countries have signed this treaty. The United States is not yet one of them although, the U.S. did vote for the treaty at the WHO meeting, and Tommy Thompson, the Secretary of Health and Human Services, has indicated support.

- The Public Affairs Committee of the Teratology Society urges the U.S. government to sign this treaty, to fully comply with its requirements and suggestions, and to expand the application of tobacco control actions as recommended above in order to specifically acknowledge the additional need for tobacco control on behalf of pregnant women and their children. 


\section{References}

Andres RL, Day MC. 2000. Perinatal complications associated with maternal tobacco use. Semin Neonatol, 5(3), p 231-241.

Castles, A, Adams, K, Melvin, CL et al. 1999. Effects of smoking during pregnancy. Five meta-analyses. American Journal of Preventive Medicine, 16, p 208-215.

Dempsey, DA and Benowitz, NL. 2001. Risks and benefits of nicotine to aid smoking cessation in pregnancy. Drug Safety, 24(4), p 277-322.

DiFranza, JR and Lew, RA. 1995. Effect of maternal cigarette smoking on pregnancy complications and sudden infant death syndrome. J Fam Pract, 40(4), p 385-94.

Ellard, GA, Johnstone, FD, Prescott, RJ, Ji-Xian, W, and Jian-Hua, M. 1996. Smoking during pregnancy: the dose-dependence of birthweight deficits. British Journal of Obstetrics and Gynecology, 103, p 806-813.

Eskenazi, B, Prehn, AW, and Christianson, RE. 1995. Passive and active maternal smoking as measured by serum cotinine: the effect on birthweight. American Journal of Public Health, 85(3), p 395-398.

Fechter, LD and Annau, Z. 1976. Effects of prenatal carbon monoxide exposure on neonatal rats. Adverse Effects of Environmental Chemicals and Psychotropic Drugs, 2, p 219- .

Fechter, LD and Annau, Z. 1977. Toxicity of mild prenatal carbon monoxide exposure. Science, 197, p 680- .

Fechter, LD and Annau, Z. 1980. Prenatal carbon monoxide exposure alters prenatal development. Neurobehavioral Toxicology, 2, p 7- .

Fingerhut LA, Kleinman JC, Kendrick JS. 1990. Smoking before, during, and after pregnancy. Am J Public Health,80, p 541-544.

Fiore MC, Bailey WC, Cohen SJ, et al. 2000. Treating Tobacco Use and Dependence. A Clinical Practice Guideline. Rockville, Md: US Dept of Health and Human Services; AHRQ publication No. 00-0032.

Haddow, JE, Knight, GJ, Palomaki, GE, and McCarthy, JE. 1988. Second trimester serum cotinine levels in nonsmokers in relation to birthweight. American Journal of Obstetrics and Gynecology, 159, p 481-484.

Hoffmann, D, Djordjevic, MV, and Hoffmann, I. 1997. The changing cigarette. Preventive Medicine, 26, p 427-434. 
Kahn, RS, Certain, L and Whitaker, RC. 2002. A Reexamination of Smoking Before, During, and After Pregnancy. American Journal of Public Health, 92(11), p 1801-1808.

Kahn, RS, Zuckerman, B, Bauchner, H, Homer, CJ and Wise, PH. 2002. Women's Health After Pregnancy and Child Outcomes at Age 3 Years: A Prospective Cohort Study. American Journal of Public Health, 92(8), p 1312-1318.

Klinnert, MD, Price, MR, Liu, AH and Robinson, JL. 2002. Unraveling the Ecology of Risks for Early Childhood Asthma Among Ethnically Diverse Families in the Southwest. American Journal of Public Health, 92(5), p 792-798.

Koren, G. 1995. Fetal toxicology of environmental tobacco smoke. Current Opinions in Pediatrics, 7, 128-135.

Kristjansson, EA, Fried, PA, and Watkinson, B. 1989. Maternal smoking during pregnancy affects children's vigilance performance. Drug and Alcohol Dependence, 24, $\mathrm{p}$ 11-19.

Lambers, DS and Clark, KE. 1996. The maternal and fetal physiologic effects of nicotine. Seminars in Perinatology, 20(2), p 115-126.

Levin, ED and Slotkin, TA. 1998. Developmental neurotoxicity of nicotine. In W Slikker and LW Chang, editors. Handbook of Developmental Neurotoxicology. San Diego: Academic Press, p 587-615.

Li, CQ, Windsor, RA, Perkins, L, et al. 1993. The impact on infant birthweight and gestational age of cotinine-validated smoking reduction during pregnancy. JAMA, 269, $\mathrm{p}$ 1519-1524.

Lichtensteiger, W, Ribary, U, Schlumpf, M, Odermatt, B, and Widmer, HR. 1988. Prenatal adverse effects of nicotine on the developing brain. In GJ Boer, MGP Feenstra, M Mirmiran, DF Swaab, and F Van Haaren, editors. Progress in Brain Research, Volume 73,Elsevier Science Publishers, p 137-157.

Luck, W and Nau, H. 1984. Nicotine and cotinine concentrations in serum and milk of nursing mothers. British Lournal of Clinical Pharmacology, 18, p 9-15.

Luck, W, Nau, H, Hansen, R and Steldinger, R. 1985. Extent of nicotine and cotinine transfer to the human fetus, placenta, and amniotic fluid of smoking mothers.

Developmental Pharmacology Therapeutics, 8, p 384-395.

Lumley, J, Oliver, S, and Waters, E. 2000. Interventions for promoting smoking cessation during pregnancy (Cochrane review). In: The Cochrane Library, Issue 2, Oxford, Update Software. 
Mactutus, CF and Fechter, LD. 1984. Prenatal exposure to carbon monoxide: learning and memory deficits. Science, 223, p 409- .

Mactutus, CF and Fechter, LD. 1985. Moderate prenatal carbon monoxide exposure produces persistent, and apparently permanent, memory deficits in rats. Teratology, 31, 1 - .

Martinez, FD, Wright, AL, Taussig, LM. 1994. The effect of paternal smoking on the birthweight of newborns whose mothers did not smoke. American Journal of Public Health, 84, p 1489-1491.

Nafsted, P, Fugelseth, D, Qvigstad, E, Zahlsen, K, and Lindemann, R. 1998. Nicotine concentration in the hair of nonsmoking mothers and size of offspring. American Journal of Public Health, 88 (1), p 120-124.

Oliveti J, Kercsmar C, Redline S. 1996. Pre- and perinatal risk factors for asthma in inner city African-American children. Am J Epidemiol. 143, p 570-577.

Peacock, JL, Bland, JM, Anderson, HR, and Brooke, OG. 1991. Cigarette smoking and birthweight: type of cigarette smoked and a possible threshold effect. International Journal of Epidemiology, 20, p 405-412.

Pickett, KE, Abrams, B, Schauffler, HH, Savage, J, Brandt, P, Kalkbrenner, A and Chapman, SA. 2001. Coverage of Tobacco Dependence Treatments for Pregnant Smokers in Health Maintenance Organizations. American Journal of Public Health, 91(9), p 1393-1394.

Pollack, HA. 2001. Sudden infant death syndrome, maternal smoking during pregnancy, and the cost-effectiveness of smoking cessation intervention. American Journal of Public Health, 91 (3), p 432-436.

Ringel, JS and Evans, WN. 2001. Cigarette Taxes and Smoking During Pregnancy. American Journal of Public Health, 91(11), p 1851-1856.

Slikker, Jr., W. and Schwetz, BA. 2003. Childhood obesity: The possible role of maternal smoking and impact on public health. Journal of Children's Health, 1 (1), p 29-40.

Streissguth, AP, Martin, DC, Barr, HM, Sandman, BM, Kirchner, GL, and Darby, BL. 1984. Intrauterine alcohol and nicotine exposure: attention and reaction time in 4-yearold children. Developmental Psychology, 20(4), p 533-541.

Taylor B and Wadsworth, J. 1987. Maternal smoking during pregnancy and lower respiratory tract illness in early life. Archives of Disease in Childhood,62, p 786-791.

Tolcos, M, McGergor, H, Walker, D, and Rees, S. 2000. Chronic prenatal exposure to carbon monoxide results in a reduction in tyrosine hydroxylase-immunoreactivity and an increase in choline acetyltransferase-immunoreactivity in the fetal medulla: implications 
for sudden infant death syndrome. Jouranl of Neuropathology and Experimental Neurology, 59(3), p 218-228.

US Department of Health and Human Services. 1990. The health benefits of smoking cessation. Rockville, MD: Office on Smoking and Health. DHHS Publication Number 90-8416.

U.S. Department of Health and Human Services. 2001. Surgeon General's Report: Women and Smoking. Chapter 2.

von Kries, R, Toschke1, AM, Koletzko, B and Slikker Jr., W. 2002. Maternal Smoking during Pregnancy and Childhood Obesity. Am. J. Epidemiol., 156 (10), p 954-961.

Walsh, RA, Lowe, JB, and Hopkins, PJ. 2001. Quitting smoking in pregnancy. MJA, 175, p 320-323.

Wang, XW, Zuckerman, B, Pearson, C, Kaufman, G, Chen, C, Wang, G, Niu, T, Wise, $\mathrm{PH}$, Bauchner, $\mathrm{H}$, and $\mathrm{Xu}, \mathrm{X}$. 2002. Maternal cigarette smoking, metabolic gene polymorphism, and infant birth weight. JAMA, 287(2), p 195-202.

Weitzman M, Gortmaker S, Walker DK, Sobol A. 1990. Maternal smoking and childhood asthma. Pediatrics, 85, p 505-511. 